\title{
The use of folic acid, iron salts and other vitamins by pregnant women in the 2015 Pelotas birth cohort: is there socioeconomic inequality?
}

Vanessa Iribarrem Avena Miranda ${ }^{1 *}$ (D), Tatiane da Silva Dal Pizzol ${ }^{2}$, Marysabel Pinto Telis Silveira', Sotero Serrate Mengue ${ }^{2}$, Mariângela Freitas da Silveira ${ }^{3}$, Bárbara Heather Lutz ${ }^{1}$ and Andréa Dâmaso Bertoldi ${ }^{1}$

\begin{abstract}
Background: Many low- and middle-income countries recommend micronutrient supplements for pregnant women to improve their nutritional status, prevent possible deficiencies and avoid fetal healgth consequences. This study evaluated the influence of socioeconomic status on the use of folic acid, iron salts and other vitamins and minerals among pregnant women in the 2015 Pelotas Birth Cohort.

Methods: This population-based birth cohort study was carried out with 4270 women. Participants were interviewed during pregnancy and at the maternity hospital about the antenatal period; including the use of iron salts, vitamins and other minerals. Descriptive analyses were performed to characterize the sample. The analyses were adjusted according to socioeconomic variables (maternal education, ethnicity, household income).

Results: The overall prevalence of the use of folic acid, iron salts or other vitamins and minerals was 91.0\% (95\% Cl: 90.1-91.8). Specifically, 70.9\% (95\% Cl: 69.5-72.3) used folic acid, 72.9\% (95\% Cl: 71.5-74.3) used iron compounds, and $31.8 \%$ (95\% Cl: 30.3-33.2) used other vitamins or minerals. In the adjusted analysis, the use of iron salts was associated with nonwhite mothers, with $\leq 4$ years of education and whose family income was less than or equal to the monthly minimum wage. The use of folic acid and other vitamins and minerals was associated with white mothers who were more highly educated and had a higher family income.

Conclusion: Although folic acid and other vitamins and minerals were more frequently used in white, richer and more educated mothers, which indicates inequality, iron supplements were more frequently used in the poorer, less educated nonwhite mothers, suggesting the opposite association for this supplement.
\end{abstract}

Keywords: Pregnant women, Folic acid, Iron salts, Vitamins, Use medication, Cohort studies

\section{Background}

Micronutrient deficiencies are common among women of reproductive age, and multiple supplements are often indicated for pregnant women. These micronutrient deficiencies may occur due to losses or malabsorption associated with disease, inadequate intake, high fertility rate, short intervals between pregnancies, lack of

\footnotetext{
* Correspondence: vanessairi@gmail.com

${ }^{1}$ Post-Graduate Program in Epidemiology, Federal University of Pelotas (UFPel), Rua Marechal Deodoro, 1160, Centro, Pelotas, RS CEP 96020-220, Brazil

Full list of author information is available at the end of the article
}

knowledge about the importance of nutrition during the antenatal period, pregnancy or physiological changes that occur during pregnancy [1-3]. Thus, many lowand middle-income countries recommend micronutrient supplements for pregnant women to improve their nutritional status, prevent possible deficiencies and avoid fetal health consequences [1-5].

Although adequate food intake remains the preferred means of meeting micronutrient requirements, some micronutrient requirements are difficult to meet during pregnancy through diet alone. The most important micronutrients during pregnancy, which are commonly

(c) The Author(s). 2019 Open Access This article is distributed under the terms of the Creative Commons Attribution 4.0 International License (http://creativecommons.org/licenses/by/4.0/) which permits unrestricted use, distribution, and reproduction in any medium, provided you give appropriate credit to the original author(s) and the source, provide a link to the Creative Commons license, and indicate if changes were made. The Creative Commons Public Domain Dedication waiver (http://creativecommons.org/publicdomain/zero/1.0/) applies to the data made available in this article, unless otherwise stated. 
obtained in the form of supplements, include vitamins A, C, D, and E; folic acid; iron; zinc; iodine; copper; selenium; and the B vitamins [2, 4].

Supplementation during the antenatal period can benefit both the mother and fetus [3]. Prophylactic use of iron salts prevents anemia and reduces the risk of low birth weight [6, 7]. Folic acid helps prevent neural tube defects [8]. Iodine can prevent cretinism and aid in fetal growth, as well as reduce the risk of stillbirths, miscarriages and anomalies [1]. Calcium is associated with reduced risks of pre-eclampsia, low birth weight and premature birth [1]. Supplementation with other minerals, such as copper, selenium, magnesium and zinc, has also been shown to reduce labor complications and contribute to fetal development $[1,2,9]$.

In response to these needs, some countries fortify selected foods and/or recommend the use of supplements during the antenatal period [6]. The World Health Organization (WHO) strongly recommends daily oral iron and folic acid supplements as part of antenatal care to reduce micronutrient deficiencies. Iron and folic acid supplements should be taken throughout the pregnancy, and the supplementation should begin as soon as possible, regardless of gestational age [6].

In Brazil, although almost all Brazilian pregnant women attend at least one antenatal visit, the proportion of women who attended six or more visits was $73 \%$ in 2012, and this percentage was lower in young women with lower socioeconomic status and those who were less educated $[10,11]$. Additionally, receiving antenatal care early in a pregnancy is common in only threequarters of women, with a lower prevalence in women who are younger, black and from the North and Northeast regions of the country [11], consistently pointing out socioeconomic inequalities in antenatal care [11, 12].

Despite the existence of health programs that recommend supplementation as a component of antenatal care, the literature indicates that the use of iron and folic acid is lower than expected [5, 12-14]. Although some studies have reported the use of supplements during pregnancy, few have focused on socioeconomic inequality in their use $[12,15,16]$, which is a very important fact, especially in low- and middle-income countries where there are diverse socioeconomic contexts [17].

Thus, the objective of this study was to analyze the influence of socioeconomic status on the use of folic acid, iron salts and other vitamins and minerals during pregnancy.

\section{Methods}

This study is part of the Pelotas Birth Cohort of 2015 (C2015), which was conducted in the city of Pelotas in southern Brazil. All women living in the urban area of Pelotas who gave birth in the city's five maternity wards between January 1 and December 31, 2015 were invited to participate. More details of the study can be found in the cohort profile paper [18].

Mothers were interviewed at the maternity hospital a few hours after delivery and responded to a standardized questionnaire about the antenatal period, including the use of folic acid, iron salts or other vitamins and minerals. The questionnaire applied was already used in a similar way in other Pelotas birth cohort studies [19-21] and is available on the website of the research center: (http://www.epidemio-ufpel.org.br/uploads/downloads/ Perinatal.pdf). In total, 4270 women were recruited for the perinatal study, representing $98.7 \%$ of all women in the eligible population [18].

A total of $75 \%$ of the women included in the perinatal study were followed up since pregnancy, which allowed us to qualify the information regarding the use of supplements during this period.

The following questions (translated to English) were used for the collection of data regarding supplement use: "Have you used or are you using any vitamin, calcium, folic acid, or iron salt supplements since you became pregnant?" For each supplement reported, the following questions were asked to characterize their usage: "Why do/did you use it?" (routine/prevention, anemia/deficiency, other), "How many days per week do/did you use it?", "Who told you to use it?" (a doctor or nurse, another person or yourself), and "In which trimester/s did you use this supplement?" (first, second or third).

The supplements were initially classified as folic acid, iron salts or vitamins and other minerals. Those containing iron salts were classified as isolated ferrous sulfate, associations of iron, other isolated forms of iron, and unspecified iron compounds. There was only one subgroup for folic acid due to the recommended daily allowance for pregnant women: folic acid associated with vitamin $\mathrm{E}$. Due to the low dosage, any other forms were classified with the other groups.

The other vitamins and minerals were classified into large groups: calcium carbonate, mineral supplements, multivitamins (including vitamins only), vitamin D, multivitamin and mineral supplements, and other vitamins.

After classifying all supplement groups, it was possible to generate the dependent variables "use of iron salts", "use of folic acid" and "use of other vitamins and minerals".

The independent variables that were analyzed were maternal age (collected in complete years and categorized as $\leq 19,20-29,30-46$ ); ethnicity (self-reported by mothers as white, black or other); parity (total number of deliveries, including stillbirths and current pregnancy; later categorized as $1,2,3$ or 4 or more); mother's 
schooling (number of years of study, later categorized into four groups: $0-4,5-8,9-11$ and 12 or more years) and family income expressed in local currency and converted into a multiple of minimum wage at the time of the perinatal interview (categorized as $\leq 1,1.1$ to 3.0, 3.1 to $6.0,6.1$ to 10 and $>10$ ). A 'minimum wage' is a measure of the legal minimum monthly salary for formal employees in Brazil.

All deliveries were performed in one of five Pelotas maternities (two medical school hospitals, one of them exclusively for users of the Unified Health System (SUS)).

Data analysis was performed using STATA $^{\circ}$, version 12.1. The sample was initially described according to the independent variables. Supplement use frequency was then calculated according to the independent variables, yielding the respective confidence intervals (95\% CIs).

Crude and adjusted analyses using Poisson regression with robust variance were carried out to verify whether the use of iron, folic acid and other vitamins and minerals differed according to socioeconomic variables. All socioeconomic variables (ethnicity, education and family income) obtained a $p$ value $<0.2$ in the crude analysis, so they were included in the adjusted analysis. A heterogeneity test and a linear trend test (ordinal variables) were performed. The variables with a $\mathrm{p}$ value $<0.05$ were considered statistically significant.

To characterize the supplements, a stratified analysis according to gestational trimester was performed. To illustrate the absolute inequality between the use of these supplements according to the trimester of use and family income, we use an equiplot, a graph illustrating the frequency of use of supplements by socioeconomic strata.

This study was approved by the Universidade Federal de Pelotas School of Physical Education Ethics Committee (522.064) and was registered in the National Ministry of Health's Plataforma Brasil. All mothers signed a free and informed consent form before being interviewed.

\section{Results}

Of the 4270 mothers who participated in C2015, 3886 (91.0, 95\% CI, 90.1-91.8) reported using folic acid, iron salts or other vitamins and minerals during pregnancy. Of these, $70.9 \%$ (95\% CI 69.5-72.3) used folic acid, $72.9 \%$ (95\% CI 71.5-74.3) used some type of iron compound and 30.3\% (95\% CI 30.3-33.2) used other vitamins or minerals. Table 1 shows the sample characteristics and prevalence of supplement use according to the studied variables. The majority of the mothers were white (70.5\%), between 20 and 29 years of age (47.3\%), had 9 to 11 years of education (34.3\%), had a family income of 1.1-3.0-times the minimum wage (47.2\%) and were experiencing their first pregnancy $(49.5 \%)$.
Table 1 Description of mothers participating in the 2015 Pelotas Birth Cohort perinatal study regarding the use of folic acid, iron salts or other vitamins and minerals ( $N=4270$ women)

\begin{tabular}{|c|c|c|c|c|c|}
\hline & \multirow[b]{2}{*}{ N } & \multirow[b]{2}{*}{$\%$} & \multicolumn{3}{|c|}{$\begin{array}{l}\text { Folic acid, iron salts or other } \\
\text { vitamins and minerals }\end{array}$} \\
\hline & & & $\mathrm{N}$ & $\%$ & IC 95\% \\
\hline \multicolumn{6}{|l|}{ Ethnicity } \\
\hline White & 3005 & 70.5 & 2765 & 92.0 & $91.0-93.0$ \\
\hline Black & 680 & 15.9 & 607 & 89.2 & 86.9-91.6 \\
\hline Other & 578 & 13.5 & 510 & 88.2 & $85.6-90.9$ \\
\hline \multicolumn{6}{|l|}{ Age (years) } \\
\hline$<=19$ years & 630 & 14.7 & 556 & 88.3 & $85.7-90.8$ \\
\hline $20-29$ & 2021 & 47.3 & 1839 & 91.0 & $89.7-92.2$ \\
\hline $30-46$ & 1618 & 37.9 & 1490 & 92.1 & $90.8-93.4$ \\
\hline \multicolumn{6}{|c|}{ Education (years) } \\
\hline $0-4$ years & 394 & 9.2 & 321 & 81.5 & $77.6-85.3$ \\
\hline $5-8$ & 1098 & 25.7 & 958 & 87.3 & $85.3-89.2$ \\
\hline $9-11$ & 1463 & 34.3 & 1346 & 92.0 & $90.6-93.4$ \\
\hline 12 or more & 1314 & 30.8 & 1261 & 96.0 & 94.9-97.0 \\
\hline \multicolumn{6}{|c|}{ Family Income (multiple of minimum wage) ${ }^{a}$} \\
\hline$\leq 1$ & 548 & 12.8 & 464 & 84.6 & $81.6-87.6$ \\
\hline $1.1-3.0$ & 2015 & 47.2 & 1810 & 89.8 & $88.5-91.1$ \\
\hline $3.1-6.0$ & 1126 & 26.4 & 1054 & 93.6 & $92.2-95.0$ \\
\hline $6.1-10.0$ & 316 & 7.4 & 299 & 94.6 & $92.1-97.1$ \\
\hline$>10.0$ & 263 & 6.2 & 258 & 98.1 & $96.4-99.8$ \\
\hline \multicolumn{6}{|l|}{ Parity } \\
\hline 1 & 2114 & 49.5 & 1988 & 94.0 & $93.0-95.0$ \\
\hline 2 & 1315 & 30.8 & 1206 & 91.7 & $90.2-93.2$ \\
\hline 3 & 472 & 11.1 & 409 & 86.7 & $83.6-89.7$ \\
\hline 4 or more & 367 & 8.6 & 282 & 76.8 & $72.5-81.2$ \\
\hline Total & 4270 & 100 & 3886 & 91.0 & $90.1-91.8$ \\
\hline
\end{tabular}

${ }^{a}$ monthly minimum wage in 2015 (R\$78 or \$201)

Pelotas, RS, Brazil, 2015

The use of folic acid, iron salts or other vitamins and minerals was more frequent in the following groups: white women, women between 30 and 46 years of age, those with 12 years or more of schooling, those with a family income over 10-times the minimum wage and those who were experiencing their first pregnancy. However, the $95 \%$ CIs of these prevalence rates overlapped in most categories (Table 1).

Considering the delivery hospitals, $46.4 \%$ of deliveries occurred in private hospitals; $35.0 \%$ occurred in a school hospital, which also attends private patients and accepts health insurance; and $18.5 \%$ occurred in a SUS hospital.

Regarding the characteristics of supplement use according to family income, the majority of supplement use was recommended by doctors or nurses, although iron and other vitamin and mineral supplements were 
recommended equally for both rich and poor women (approximately 98\%). Folic acid was recommended for $99.0 \%$ the poorest mothers, compared to $95.0 \%$ of the richest mothers. Routine/prevention was the most commonly reported reason for using iron salts, and the reasons were equally distributed between the richest and the poorest mothers. For folic acid and other vitamins and minerals, the most commonly reported reason for use was routine/prevention (92.4 and 69.3\%, respectively), differing between rich (97.0 and $74.4 \%$, respectively) and poor mothers (87.0 and $62.3 \%$, respectively). Poor mothers more frequently cited deficiency, while richer mothers reported the usage as routine (data not shown in the table).

Folic acid use declined closer to delivery, falling from $62.0 \%$ in the first trimester (T1) to $15.2 \%$ in the third trimester (T3) (Fig. 1). The opposite occurred with iron salts; the use in T3 was $60.7 \%$. The use of the other vitamins and minerals totaled $14.1 \%$ of all supplements in $\mathrm{T} 1$ and $25.3 \%$ in T3. The frequency of the use of the other vitamins and minerals was $13.0 \%$ in $\mathrm{T} 1$ and $23.2 \%$ in $\mathrm{T} 3$.

Figure 2 shows the use of folic acid, iron salts and other vitamins and minerals according to trimester and family income. In the first trimester of pregnancy, folic acid was more frequently used by the richest mothers with family incomes between 6.1-10-times the minimum wage $(67.0 \%)$ and $>10$-times the minimum wage (77.6\%). Iron salts were more frequently used in the poorest mothers, regardless of the trimester. Other vitamins and minerals were more frequently used in the richest mothers ( $>10$-times the minimum wage) during all trimesters $(p<0.005$ for all values).

Table 2 describes the socioeconomic factors associated with the use of folic acid and iron salts separately. In both the crude and adjusted analyses, all variables were significantly associated with both outcomes. In the adjusted analysis of folic acid use, black mothers used folic acid $9.0 \%$ less than white mothers. Women with 4 years or less of education used $22.0 \%$ less folic acid than those who were better educated. The use of folic acid was $17.0 \%$ lower among mothers with lower family income than among the wealthiest mothers.

Nonwhite mothers used up to $8.0 \%$ more iron salts than white mothers. Women with $\leq 4$ years of schooling used $46.0 \%$ more iron salts than those with more education. In addition, those with a family income $\leq 1$-times the minimum wage used iron more frequently (39.0\%).

The adjusted analysis of other vitamins and minerals showed that mothers who were white, more educated and had higher incomes used more vitamins and minerals than any other group (Table 3 ).

\section{Discussion}

The findings of the present study were a $91 \%$ overall prevalence of supplement use, a result similar to those obtained by Forster et al. in Australia [5] and Bagheri et al. in Iran [22], who found that $92.7 \%$ of the women used some multivitamin during pregnancy. However, the majority of similar studies have found lower prevalences, ranging from 70.3 to $88.7 \%$ [23-26].

The prevalence of folic acid and iron compound use was 70.9 and $72.9 \%$, respectively. The use of these supplements during pregnancy is advocated by both the WHO and the Brazilian Ministry of Health, which recommend the use of these supplements for all pregnant women as part of antenatal care [6, 27]. An Australian study [5] of women in the immediate postpartum period revealed iron and folic acid use of 52.0 and $79.0 \%$, respectively, during pregnancy, while a study from Portugal found

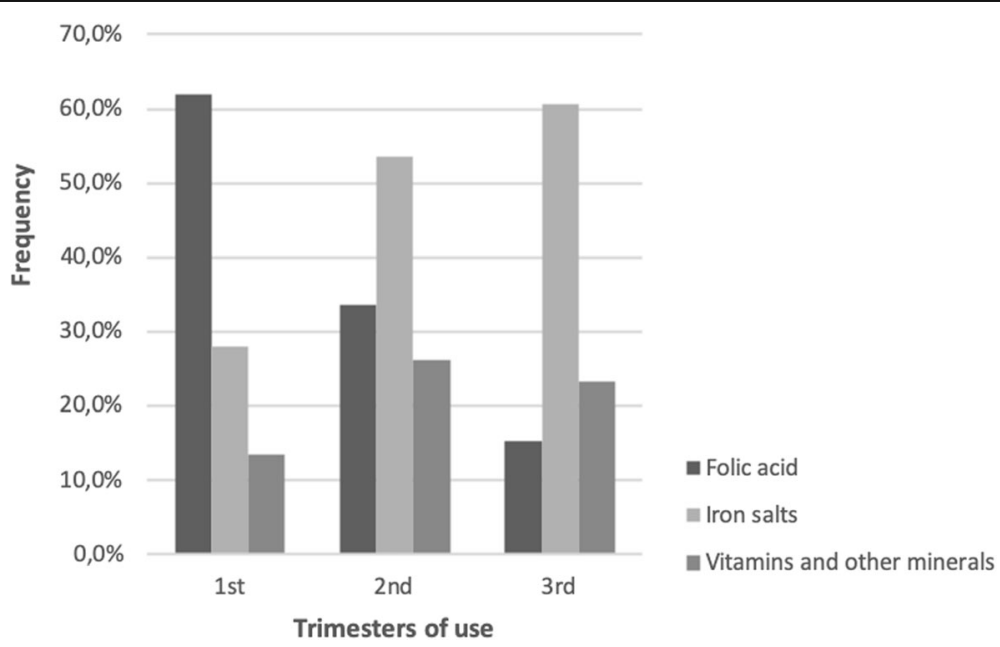

Fig. 1 Use of folic acid, iron salts and other vitamins and minerals among pregnant women in the Pelotas Birth Cohort ( $N=4270$ women). Pelotas, RS, Brazil, 2015 


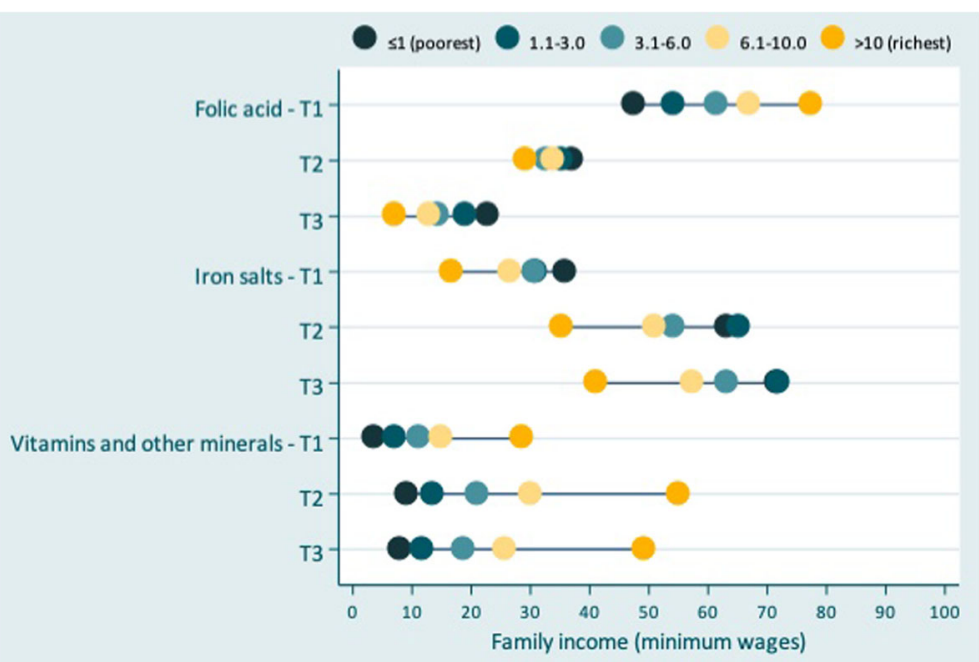

Fig. 2 Use of folic acid, iron salts and other vitamins and minerals among pregnant women in the Pelotas Birth Cohort according to the trimester of use and family income ( $N=4270$ women). Pelotas, RS, Brazil, 2015

prevalence rates of 55.4 and $81.9 \%$ for iron and folic acid use, respectively [26]. On the other hand, an Italian cohort study of 1000 women found a prevalence of iron salt use of $95.0 \%$ [28]. Lower prevalences of folic acid use, approximately 30.0\%, were found by Mezzomo, et al. [29] and Barbosa et al. [14] in Brazil.
With respect to iron supplementation, these differences could be attributable to different social contexts and regional variations in recommendations, a factor especially present in low- and middle-income countries where dietary iron intake is often insufficient $[15,17]$. Regarding the trend of iron use according to the trimester

Table 2 Prevalence of folic acid and iron salt use by pregnant women in the 2015 Pelotas Birth Cohort perinatal study, crude and adjusted prevalence ratios and respective confidence intervals (95\% Cl) ( $N=4270$ women)

\begin{tabular}{|c|c|c|c|c|c|c|c|c|c|c|}
\hline & \multicolumn{5}{|c|}{ Iron salts } & \multicolumn{5}{|c|}{ Folic acid } \\
\hline & \multicolumn{3}{|c|}{ Crude analysis } & \multicolumn{2}{|c|}{ Adjusted analysis $^{a}$} & \multicolumn{3}{|c|}{ Crude analysis } & \multicolumn{2}{|c|}{ Adjusted analysis $^{a}$} \\
\hline & & & $95 \% \mathrm{Cl}$ & & $95 \% \mathrm{Cl}$ & & & $95 \% \mathrm{Cl}$ & & $95 \% \mathrm{Cl}$ \\
\hline & P (\%) & $P R$ & ( $p$ value) & PR & ( $p$ value) & $\mathrm{P}(\%)$ & $P R$ & ( $p$ value) & PR & ( $p$ value) \\
\hline Ethnicity & & & $(<0.001)$ & & $(<0.001)$ & & & $(<0.001)$ & & $(0.03)$ \\
\hline White & 68.2 & 1 & & 1 & & 73.4 & 1 & & 1 & \\
\hline Other & 85.8 & 1.25 & $1.20-1.31$ & 1.11 & $1.07-1.16$ & 66.6 & 0.90 & $0.85-0.96$ & 0.97 & $0.91-1.03$ \\
\hline Black & 82.8 & 1.21 & $1.15-1.27$ & 1.08 & $1.03-1.13$ & 62.4 & 0.85 & $0.79-0.91$ & 0.91 & $0.85-0.98$ \\
\hline Education (years) & & & $<0.001$ & & $<0.001$ & & & $(<0.001)$ & & $(<0.001)^{c}$ \\
\hline$\leq 4$ years & 90.6 & 1.72 & $1.61-1.83$ & 1.46 & $1.36-1.56$ & 58.6 & 0.71 & $0.65-0.79$ & 0.78 & $0.71-0.86$ \\
\hline $5-8$ & 87.4 & 1.66 & $1.56-1.75$ & 1.45 & $1.35-1.53$ & 62.7 & 0.77 & $0.72-0.81$ & 0.82 & $0.77-0.87$ \\
\hline $9-11$ & 77.3 & 1.46 & $1.38-1.56$ & 1.31 & $1.23-1.40$ & 69.9 & 0.86 & $0.82-0.89$ & 0.88 & $0.84-0.93$ \\
\hline$\geq 12$ & 52.6 & 1 & & 1 & & 81.3 & 1 & & 1 & \\
\hline Family Income b & & & $(<0.001)$ & & $(<0.001)$ & & & $(<0.001)$ & & $(0.02)^{c}$ \\
\hline$\leq 1$ & 86.4 & 1.93 & $1.68-2.23$ & 1.39 & $1.20-1.61$ & 57.9 & 0.68 & $0.61-0.74$ & 0.82 & $0.74-0.90$ \\
\hline $1.1-3.0$ & 80.7 & 1.81 & $1.57-2.07$ & 1.39 & $1.20-1.59$ & 68.3 & 0.80 & $0.75-0.85$ & 0.91 & $0.85-0,97$ \\
\hline $3.1-6.0$ & 67.3 & 1.50 & $1.30-1.74$ & 1.28 & $1.11-1.48$ & 75.8 & 0.88 & $0.83-0.94$ & 0.95 & $0.89-1.01$ \\
\hline $6.1-10.0$ & 48.8 & 1.10 & $0.91-1.31$ & 1.06 & $0.89-1.26$ & 77.6 & 0.90 & $0.84-0.98$ & 0.92 & $0.85-1.00$ \\
\hline$>10.0$ & 44.6 & 1 & & 1 & & 85.3 & 1 & & 1 & \\
\hline
\end{tabular}

${ }^{a}$ Model adjusted for ethnicity, family income and years of education

${ }^{\mathrm{b}}$ Monthly minimum wage in 2015 (R\$788 or \$201)

c $p$-value: $x^{2}$ test for trend

Pelotas, RS, Brazil, 2015 
Table 3 Prevalence of the use of other vitamins and minerals by pregnant women in the 2015 Pelotas Birth Cohort perinatal study, crude and adjusted prevalence ratios and respective confidence intervals (95\% Cl) (N=4270 women)

\begin{tabular}{|c|c|c|c|c|c|c|c|}
\hline & \multicolumn{4}{|c|}{ Crude analysis } & \multicolumn{3}{|c|}{ Adjusted analysis $^{a}$} \\
\hline & $\mathrm{P}(\%)$ & $P R$ & $95 \% \mathrm{Cl}$ & ( $p$ value) & $P R$ & $95 \% \mathrm{Cl}$ & ( $p$ value) \\
\hline Ethnicity & & & & $<0.001$ & & & $<0.001$ \\
\hline White & 62.7 & 1 & & & 1 & & \\
\hline Other & 18.3 & 0.49 & $0.41-0.58$ & & 0.77 & $0.65-0.91$ & \\
\hline Black & 17.8 & 0.48 & $0.39-0.58$ & & 0.73 & $0.61-0.86$ & \\
\hline Education (years) & & & & $<0.001$ & & & $<0.001$ \\
\hline$\leq 4$ years & 6.9 & 1 & & & 1 & & \\
\hline $5-8$ & 11.7 & 1.70 & $1.10-2.64$ & & 1.50 & $0.97-2.33$ & \\
\hline $9-11$ & 26.0 & 3.80 & $2.50-5.73$ & & 2.91 & $1.91-4.43$ & \\
\hline$\geq 12$ & 59.6 & 8.70 & $5.79-13.0$ & & 5.22 & $3.44-7.93$ & \\
\hline Family Income ${ }^{b}$ & & & & $<0.001$ & & & $<0.001$ \\
\hline$\leq 1$ & 10.8 & 1 & & & 1 & & \\
\hline $1.1-3.0$ & 20.9 & 1.94 & $1.47-2.56$ & & 1.37 & $1.04-1.80$ & \\
\hline $3.1-6.0$ & 40.2 & 3.73 & $2.84-4.90$ & & 1.86 & $1.41-2.44$ & \\
\hline $6.1-10.0$ & 67.2 & 6.23 & $4.74-8.20$ & & 2.37 & $1.78-3.15$ & \\
\hline$>10.0$ & 70.2 & 6.51 & $4.95-8.55$ & & 2.35 & $1.76-3.10$ & \\
\hline
\end{tabular}

a Model adjusted for ethnicity, family income and years of education

${ }^{b}$ Monthly minimum wage in 2015 (R\$788 or \$201)

Pelotas, RS, Brazil, 2015

of pregnancy, the increase in use in the third trimester may be due to the fact that many mothers discover pregnancy and begin antenatal care with the most advanced pregnancy, thus not having access to the recommendation of use in the first and/or second trimester of pregnancy. In addition, in the third trimester there are more pregnant women with iron deficiency anemia, which increases adherence to the recommendations of using iron salts [27, 30, 31].

Differences in folic acid use could be due to differences between protocols. During the study period, the current protocol in Brazil recommended the use of folic acid in the pre-conception and during the first trimester only [27]. However a more recent protocol recommends the use of folic acid during all period of pregnancy [32]. In addition, this supplement is often not prescribed when a woman's antenatal care begins at a late stage. However, for women seeking preconception counseling, there is a high chance that it will be prescribed for the all gestational period.

So, despite the fact that iron and folic acid are commonly prescribed in most countries, in addition to the reasons mentioned above, nonuse by pregnant women persists for others variety of reasons. For iron, for example, these include adverse reactions and ignorance of its importance [15]. There is also controversy in the literature about the benefits and possible side effects of iron use by non-anemic mothers [33, 34].
Consistent with the literature, we found that the use of supplements in general was more prevalent among white women [29, 35], older women [34, 35], those with a higher education level $[9,14,29]$ and those with a higher income $[15,24,29]$. Although these characteristics suggest some inequality, their differences were not significant. Multiparous women used fewer supplements than those experiencing their first pregnancy. This difference is perhaps due to greater concern for the first child, which diminishes somewhat with subsequent pregnancies, given that prior experience and changes in attitudes about health make the mother less insecure $[15,36]$.

The characteristics of folic acid, iron salt and other vitamin and mineral use indicate that practically all supplements used during antenatal care were recommended by doctors $[16,25]$. Regarding the different reasons for use, $49.8 \%$ of women in the iron salts group were treating a deficiency, while for folic acid and other vitamins and minerals, the most frequently reported reason was routine prevention. This difference could be due to increased clinical and laboratory monitoring of iron deficiency anemia compared with that of other micronutrient deficiencies.

The results for the use of each supplement according to trimester and family income are in agreement with the findings of the stratified analysis. Regarding iron salts, the results showed that the nonwhite, poorer and less educated mothers used them more, which would 
seem to suggest that iron supplementation is more frequent among poorer and nutritionally vulnerable women going in the same direction of the results pointed out by the study of Tomasi et al. 2017, which included all the basic health units in Brazil and found prevalence of iron prescriptions of almost $100 \%$ among women with the same characteristics [12]. However the opposite has been found in other studies $[15,16]$, and this difference may be related to the fact that, in Brazil, prenatal coverage is considered high, and women who use public health services the most are the poorest.

Unlike the use of iron salts, the use of folic acid and other vitamins and minerals reflected different user profiles, i.e., white, wealthier and more educated $[9,13-16,26,35]$. This difference could be due to the fact that poorer mothers seek health services later in pregnancy when folic acid would no longer be recommended, whereas mothers with better purchasing power and greater access to information would tend to have a planned pregnancy and, thus, a greater chance of beginning antenatal care (and supplementation) early in $\mathrm{T} 1[15,16]$.

Our study has the advantage of being a cross-sectional study nested in a population-based cohort, which provides more timely information about supplement use. However, it also has some limitations. No information regarding dose or adherence was analyzed. However, the fact that iron salts, vitamins and other minerals were used on average 6.9 days per week can be considered a proxy for the continuity of treatment.

The elapsed time between supplement use and the interview can lead to recall error and underestimation of prevalence. Nevertheless, a recent study demonstrated good agreement between short recall periods for continuously used drugs [37]. In addition, the supplement use data collected during antenatal care minimizes this problem.

Since part of the sample did not participate in the antenatal study, subgroup analyses were conducted. The results indicated no differences in the prevalence of iron salt use among those who participated only in the perinatal study. However, there was a lower prevalence of the use of other compounds in this group. Thus, there may have been an underestimation of the general use of folic acid, iron salts and other vitamins and minerals when analyzed separately.

\section{Conclusion}

This exploration of socioeconomic differences in the use of supplements found inequalities in the use of folic acid and other vitamins and minerals in favor of the richer and more educated white mothers, but in the case of vitamins and other minerals, there are no recommendations for their use or evidence of well-established benefits in the pregnant population.
However, in the case of folic acid, this inequality is relevant since it is universally recommended and has well-established benefits. Regarding the use of iron salts, the opposite occurred: an inequality favored nonwhite, less educated and poorer mothers. This suggests equity in access and demonstrates the reach of this important public health policy.

Thus, it is concluded that the existing recommendations are sufficient, however, it is necessary that there is an incentive to the early initiation of antenatal care, promotion of the knowledge of the pregnant women and the health professionals of the area on the importance of the use of the folic acid and iron salts in the gestational period, in order to increase the adherence to the recommendations.

\section{Abbreviations \\ C2015: Pelotas Birth Cohort of 2015; Cl: Confidence interval; T1: First trimester; T2: Second trimester; T3: Third trimester; WHO: World Health Organization}

\section{Acknowledgements}

Not applicable.

\begin{abstract}
Authors' contributions
VIAM, TSDP, MPTS, SSM and BHL contributed to the analysis, writing the manuscript and the final review. MFS and ADB contributed to the design, data collection and logistics of the study, as well as writing the manuscript and final review. All authors read and approved the final manuscript.
\end{abstract}

\section{Funding}

This article is based on data from the study "Pelotas Birth Cohort, 2015" conducted by Postgraduate Program in Epidemiology at Universidade Federal de Pelotas, with the collaboration of the Brazilian Public Health Association (ABRASCO). The 2015 Pelotas (Brazil) Birth Cohort is funded by the Wellcome Trust (095582). Funding for specific follow-up visits was also received from the Conselho Nacional de Desenvolvimento Científico e Tecnológico (CNPq) and Fundação de Amparo a Pesquisa do Estado do Rio Grande do Sul (FAPERGS). All funding body contributed to the design of the study and collection of data. The CNPq contributed to data analysis and manuscript writing.

\section{Availability of data and materials}

The datasets generated and/or analyzed during the current study are not publicly available because they are extremely long and costly, both in terms of the money and time involved in project writing and data collection, which involves complex data and local specificities. Thus, responsible use of the data includes knowledge of the study design and objectives and of the local health system. However, data can be made available by the 2015 cohort team coordinator on reasonable request and agreement.

\section{Ethics approval and consent to participate}

The study was approved by the Research Ethics Committee at the Federal University of Pelotas Medical School (CEP/UFPEL) under the number 522.064 Mothers who agreed to undergo an interview entered the study after signing free informed consent. Voluntary participation was guaranteed by explaining to the participants they could withdraw from the study at any time without providing any reason. The confidentiality of the provided information was assured.

Consent for publication

The authors agree to the publication of this manuscript.

Competing interests

The authors declare that they have no competing interests. 


\section{Author details}

${ }^{1}$ Post-Graduate Program in Epidemiology, Federal University of Pelotas (UFPel), Rua Marechal Deodoro, 1160, Centro, Pelotas, RS CEP 96020-220, Brazil. ${ }^{2}$ Post-Graduate Program in Epidemiology, Federal University of Porto Alegre, Av. Ipiranga, 2752, sala 203 Porto Alegre, RS - Brasil, Porto Alegre CEP 90610-000, Brazil. ${ }^{3}$ Faculty of Medicine, Maternal and Child Department, Post-Graduate Program in Epidemiology, Federal University of Pelotas, Rua Marechal Deodoro, 1160, Centro, Pelotas, RS CEP 96020-220, Brazil.

Received: 3 September 2018 Accepted: 30 June 2019 Published online: 05 July 2019

\section{References}

1. Ladipo OA. Nutrition in pregnancy: mineral and vitamin supplements. Am J Clin Nutr. 2000;72(1):280s-90s.

2. Darnton-Hill I, Mkparu UC. Micronutrients in pregnancy in low-and middleincome countries. Nutrients. 2015. https://doi.org/10.3390/nu7031744.

3. Haider BA, Bhutta ZA. Multiple-micronutrient supplementation for women during pregnancy. Cochrane Database Syst Rev. 2015. https://doi.org/10.1 002/14651858

4. Gernand AD, Schulze KJ, Stewart CP, West KP Jr, Christian P. Micronutrient deficiencies in pregnancy worldwide: health effects and prevention. Nat Rev Endocrinol. 2016;12(5):274-89. https://doi.org/10.1038/nrendo.2016.37.

5. Forster DA, Wills G, Denning A, Bolger M. The use of folic acid and other vitamins before and during pregnancy in a group of women in Melbourne, Australia. Midwifery. 2009;25(2):134-46.

6. World Health Organization. Guideline: daily iron and folic acid supplementation in pregnant women: World Health Organization; 2012. http://apps.who.int/iris/handle/10665/77770. Accessed 6 Apr 2018

7. Ministério da Saúde do Brasil. Programa Nacional de Suplementação de Ferro - Manual de Condutas Gerais. Ministério da Saúde Braślia; 2013. http://bvsms.saude.gov.br/bvs/publicacoes/manual_suplementacao_ferro_ condutas gerais.pdf. Accessed 2 Mar 2018.

8. Chitayat D, Matsui D, Amitai Y, Kennedy D, Vohra S, Rieder M, et al. Folic acid supplementation for pregnant women and those planning pregnancy: 2015. J Clin Pharmacol. 2016;56(2):170-5. https://doi.org/10.1002/jcph.616.

9. Johnston EO, Sharma AJ, Abe K. Association Between Maternal Multivitamin Use and Preterm Birth in 24 States, Pregnancy Risk Assessment Monitoring System, 2009-2010. Maternal Child Health J. 2016;20(9):1825-34. https://doi. org/10.1007/s10995-016-1985-1.

10. Rasia ICRB, Albernaz E. Atenção pré-natal na cidade de Pelotas, Rio Grande do Sul, Brasil. Rev Bras Saúde Matern Infant. 2008:8:401-10.

11. Viellas Elaine Fernandes, Domingues Rosa Maria Soares Madeira, Dias Marcos Augusto Bastos, Gama Silvana Granado Nogueira da, Theme Filha Mariza Miranda, Costa Janaina Viana da et al. Assistência pré-natal no Brasil. Cad Saúde Pública 2014; 30 (Suppl 1): S85-S100. https://doi.org/10.1590/01 02-311X00126013.12.

12. Tomasi Elaine, Fernandes Pedro Agner Aguiar, Fischer Talita, Siqueira Fernando Carlos Vinholes, da Silveira Denise Silva, Thumé Elaine et al. Qualidade da atenção pré-natal na rede básica de saúde do Brasil: indicadores e desigualdades sociais. Cad Saúde Pública. 2017; 33(3): e00195815. Epub Apr 03, 2017. https://doi.org/10.1590/0102-311×00195815.

13. Linhares $\mathrm{AO}$, Cesar JA. Suplementação com ácido fólico entre gestantes no extremo Sul do Brasil: prevalência e fatores associados. Ciênc saúde coletiva. 2017;22:535-42. https://doi.org/10.1590/1413-81232017222.06302016.

14. Barbosa L, Ribeiro Dde Q, de Faria FC, Nobre LN, Lessa Ado C. Factors associated with folic acid use during pregnancy. Rev Bras Ginecol Obstet. 2011;33(9):246-51.

15. Titilayo A, Palamuleni ME, Omisakin O. Sociodemographic factors influencing adherence to antenatal iron supplementation recommendations among pregnant women in Malawi: analysis of data from the 2010 Malawi demographic and health survey. Malawi Med J. 2016;28(1):1-5.

16. Nisar YB, Dibley MJ, Mir AM. Factors associated with non-use of antenatal iron and folic acid supplements among Pakistani women: a cross sectional household survey. BMC Pregnancy Childbirth. 2014;14:305. https://doi.org/1 0.1186/1471-2393-14-305.

17. World Health Organization (WHO). WHO recommendations on antenatal Care for a Positive Pregnancy Experience: summary. Geneva: WHO; 2018. https:/apps.who.int/iris/bitstream/handle/10665/259947/WHO-RHR-18.02eng.pdf;jsessionid=8A3C9A947556B939590227EDAECCADD9? sequence=1, Accessed 5 Apr 2019
18. Hallal PC, Bertoldi AD, Domingues MR, Silveira MFD, Demarco FF, da Silva ICM, et al. Cohort profile: the 2015 Pelotas (Brazil) birth cohort study. Int J Epidemiol. 2017. https://doi.org/10.1093/ije/dyx219.

19. Bertoldi AD, da Silva Dal Pizzol T, Camargo AL, Barros AJ, Matijasevich A, Santos IS. Use of medicines with unknown fetal risk among parturient women from the 2004 Pelotas Birth Cohort (Brazil). J Pregnancy. 2012;2012: 257597 Epub 2013/01/25.

20. LA-Ohoo T-R, Schneider BC, Martins-Silva T, Del-Ponte B, Loret de Mola C, Schuler-Faccini $L$, et al. Is intrauterine exposure to acetaminophen associated with emotional and hyperactivity problems during childhood? Findings from the 2004 Pelotas birth cohort. BMC Psychiatry. 2018;18(1):368. https://doi.org/10.1186/s12888-018-1942-1.

21. Santos IS, Barros Aj Fau - Matijasevich A, Matijasevich A Fau - Domingues MR, Domingues Mr Fau - Barros FC, Barros FC Fau - Victora CG, Victora CG. Cohort profile: the 2004 Pelotas (Brazil) birth cohort study. Int J Epidemiol. (1464-3685 (Electronic)).

22. Azam Bagheri NE, Abbaszadeh F. Self-medication and supplement use by pregnant women in Kashan rural and urban areas. J Mazandaran Univ Med Sci. 2014:24(114):151-7.

23. Gomes KR, Moron AF, Silva R, Siqueira AA. Prevalence of use of medicines during pregnancy and its relationship to maternal factors. Rev Saúde Pública. 1999:33(3):246-54. https:/doi.org/10.1590/50034-89101999000300005.

24. Sullivan KM, Ford ES, Azrak MF, Mokdad AH. Multivitamin use in pregnant and nonpregnant women: results from the behavioral risk factor surveillance system. Public Health Rep. 2009;124(3):384-90.

25. Holguín-Hernández Esperanza O-DJG. Administración de ácido fólico y otros micronutrientes en mujeres embarazadas de Colombia. Rev bol ped. 2013; 52(3):143-54.

26. Lunet N, Rodrigues T, Correia S, Barros H. Adequacy of prenatal care as a major determinant of folic acid, iron, and vitamin intake during pregnancy. Cad Saude Publica. 2008;24(5):1151-7.

27. Ministério da Saúde do Brasil. Atenção ao pré-natal de baixo risco. Cadernos de Atenção Básica, n 32. 2013. http://189.28.128.100/dab/docs/portaldab/ publicacoes/caderno_32.pdf. Accessed 2 Mar 2018.

28. Bo S, Menato G, Villois P, Gambino R, Cassader M, Cotrino I, et al. Iron supplementation and gestational diabetes in midpregnancy. Am J Obstet Gynecol. 2009;201(2):158.e1-6. https://doi.org/10.1016/j.ajog.2009.04.049.

29. Mezzomo CL, Garcias Gde L, Sclowitz ML, Sclowitz IT, Brum CB, Fontana T, et al. Prevention of neural tube defects: prevalence of folic acid supplementation during pregnancy and associated factors in Pelotas, Rio Grande do Sul state, Brazil. Cad Saude Publica. 2007;23(11):2716-26.

30. World Health Organization (WHO). Worldwide prevalence of anaemia 19932005: WHO global database on anaemia. 2008. https://apps.who.int/iris/ bitstream/handle/10665/43894/9789241596657_eng.pdf;jsessionid=84C621 83DB00A4461D68890049ACD390? sequence=1 Accessed 5 Apr 2019.

31. Miranda VIA, Santos IS, Silveira MFD, Silveira MPT, Pizzol T, Bertoldi AD. Validity of patient-reported anemia and therapeutic use of iron supplements during pregnancy: 2015 Pelotas (Brazil) birth cohort. Cad Saude Publica. 2018;34(6):e00125517.

32. Ministério da Saúde. Protocolos da Atenção Básica : 1.1. Protocolos da Atenção Básica : Saúde das Mulheres / Ministério da Saúde, Instituto SírioLibanês de Ensino e Pesquisa - Brasília : Ministério da Saúde, 2016. 2016.

33. Helin A, Kinnunen TI, Raitanen J, Ahonen S, Virtanen SM, Luoto R. Iron intake, haemoglobin and risk of gestational diabetes: a prospective cohort study. BMJ Open. 2012;2(5):e001730. https://doi.org/10.1136/bmjopen-2012-001730.

34. Javadian P, Alimohamadi S, Gharedaghi MH, Hantoushzadeh S. Gestational diabetes mellitus and iron supplement; effects on pregnancy outcome. Acta Med Iran. 2014;52(5):385.

35. Yu SM, Keppel KG, Singh GK, Kessel W. Preconceptional and prenatal multivitamin-mineral supplement use in the 1988 National Maternal and infant health survey. Am J Public Health. 1996;86(2):240-2.

36. Beria JU, Victora CG, Barros FC, Teixeira AB, Lombardi C. Epidemiology of drug consumption in children of a urban center of the southern region of Brazil. Rev Saude Publica. 1993;27(2):95-104.

37. Moraes CG, Mengue SS, Pizzol T. Agreement between different recall periods in drug utilization studies. Rev bras de epidemiol. 2017;20(2):324-34. https://doi.org/10.1590/1980-5497201700020012.

\section{Publisher's Note}

Springer Nature remains neutral with regard to jurisdictional claims in published maps and institutional affiliations. 